\title{
Nanodiamond enhances immune responses in mice against recombinant $\mathrm{HA}$ / H7N9 protein
}

\author{
Ngoc Bich Pham ${ }^{1,2}$, Thuong Thi Ho1, Giang Thu Nguyen'1, Thuy Thi Le1, Ngoc Thu Le', Huan-Cheng Chang ${ }^{3}$, \\ Minh Dinh Pham ${ }^{1,3}$, Udo Conrad ${ }^{4}$ and Ha Hoang $\mathrm{Chu}^{1,2^{*}}$
}

\begin{abstract}
Background: The continuing spread of the newly emerged H7N9 virus among poultry in China, as well as the possibility of human-to-human transmission, has attracted numerous efforts to develop an effective vaccine against H7N9. The use of nanoparticles in vaccinology is inspired by the fact that most pathogens have a dimension within the nano-size range and therefore can be processed efficiently by the immune system, which leads to a potent immune response. Herein, we report a facile approach to increase antigen size to achieve not only fast but also effective responses against the recombinant HA/H7N9 protein via a simple conjugation of the protein onto the surface of nanodiamond particles.
\end{abstract}

Results: In this study, trimeric Haemagglutinin ( $\mathrm{H} 7$ ) that is transiently expressed in $\mathrm{N}$. benthamiana was purified using affinity chromatography, and its trimeric state was revealed successfully by the cross-linking reaction. The trimeric $\mathrm{H} 7$ solution was subsequently mixed with a nanodiamond suspension in different ratios. The successful conjugation of the trimeric $\mathrm{H} 7$ onto the surface of nanodiamond particles was demonstrated by the changes in size and Zetapotential of the particles before and after protein coating, Sodium dodecyl sulfate polyacrylamide gel electrophoresis (SDS-PAGE), and Western-blot analysis. Next, biofunction of the protein-nanodiamond conjugates was screened using a haemagglutination assay. A mixture containing $5 \mu \mathrm{g}$ of trimeric $\mathrm{H} 7$ and $60 \mu \mathrm{g}$ of nanodiamond corresponds to a ratio of 1:12 (w/W) of agglutinated chicken red blood cells at HA titer of 1024, which is 512-fold higher than the HA titer of free trimeric H7. After the 2nd and 3rd immunization in mice, ELISA and Western blot analyses demonstrated that the physical mixture of trimeric $\mathrm{H} 7$ protein and nanodiamond $(1: 12, \mathrm{~W} / \mathrm{W})$ elicited statistically significant stronger H7-specific-lgG response demonstrated by higher amounts of H7N9-specific lgG (over 15.4-fold with $\mathrm{P}<0.05$ after the second immunization).

Conclusions: These results indicated a potential effect inherent to nanodiamond towards modulating immune systems, which should be further evaluated and broadly applied in nanovaccine development.

Keywords: Nanodiamond, Recombinant H7 haemagglutinin, Influenza virus A/H7N9, Synthetic virus-like particles, Plant-derived protein

\section{Background}

Vaccination is one of the most effective and cost-beneficial interventions that prevent mortality and reduce morbidity caused by pathogens such as influenza viruses [22].

\footnotetext{
*Correspondence: chuhoangha@ibt.ac.vn

${ }^{1}$ Institute of Biotechnology, Vietnam Academy of Science

and Technology, Ha Noi, Vietnam

Full list of author information is available at the end of the article
}

To improve host immune responses against continuing and emerging viral threats, vaccine technology continues to put great efforts to integrating virus-like features in vaccine formulations. Recent studies have illustrated that vaccines that preserve virus-like features showed better capability in eliciting immune responses in comparison with traditional vaccine formulations $[1,6,10,16]$. 
In recent years, nanoparticles have been considered as an interesting component for experimental vaccine formulations [32]. The use of nanoparticles in vaccinology is inspired by the fact that most pathogens have dimensions in the nano-size range [31], and therefore can be processed efficiently by the immune system, which leads to a potent immune response. Therefore, nanoparticles are being exploited to elicit desired immune responses for both prophylactic and therapeutic effects. They are utilized either as a delivery system to enhance antigen processing or to protect antigen from premature degradation and/or as an immune stimulant to trigger immune responses [26]. Nanotechnology allows customization of the nanoparticle properties, such as size, shape and surface charge, to meet application requirements, which results in a significant variety of nanoparticles.

Nanodiamond (ND) is a carbon nanomaterial that has been applied in many fields of research $[8,14,17,18]$. With excellent mechanical and optical properties, high surface areas, tunable surface structures and biocompatibility, nanomaterials are well suited to biomedical applications. Previous studies have shown that strong acid-oxidized NDs have a remarkably high affinity for proteins $[2,11]$. Thus, proteins and NDs can form stable conjugates easily and effectively in different buffers via physical absorption. It is also unique that both soluble proteins and native membrane proteins solubilized in detergent micelles can be easily conjugated onto the surface of NDs, likely due to the intrinsic hydrophobicity of the carbon-based nanomaterial $[17,18]$. This characteristic allows a facile and effective loading of a high amount of protein molecules on their surface for bio-medical applications. For $\sim 100 \mathrm{~nm}$ NDs, a 20-30- $\mathrm{gg}$ weight of nanoparticles can carry a $1 \mu \mathrm{g}$ dried weight of protein $[2$, 17].

Influenza viruses are serious global pathogens and are deemed to be one of the biggest threats to human and animal health. Avian influenza A (H7N9) virus emerged as a new human pathogen in China in spring of 2013. By February 2015, 571 human H7 infected cases have been reported including 212 deaths [29]. H7N9 viruses, along with many other emerging influenza subtypes, challenge scientists to develop faster and more efficacious vaccines. Haemagglutinin (HA), which is the major protein of influenza H7N9 virus envelope, contains virus-neutralizing epitopes and is included in all currently approved human influenza vaccines as well as in majority of experimental vaccines [5]. Native influenza HA protein is polymerized as a trimer. It seems that the recombinant HA fragments themselves cannot easily form a functional when expressing in different systems without motif fusion.
The recombinant subunit vaccine technology is a promising approach for developing novel influenza vaccines due to the advantages in safety and manufacturing. These vaccines have been shown to be efficacious against influenza over attenuated or inactivated vaccines [23, 24]. Some recent studies have shown that the H7N9 recombinant virus-like particle (VLP) vaccine induced protective immunity against the H7N9 virus in model animals $[9,12,23]$. However, production of these recombinant VLP vaccines is time-consuming. Plants have shown to be one of the most promising alternative pharmaceutical production platforms that are robust, scalable, low-cost and safe. A rapid H7-VLP vaccine development (19 days) from Nicotiana benthamiana is performed using an agro-infiltration-elicited protective immune response against the H7N9 influenza virus [21].

In the context of this study, an H7 fused GCN4-pII motif trimer (designated as H7) was physically mixed with NDs in an optimized ratio to generate oligomeric H7 as a synthetic H7-VLP formation. Trimeric H7 was expressed in $N$. benthamiana, purified via affinity chromatography (IMAC), characterized via a crosslinking reaction, and then incubated with a mixture of 50-500 $\mathrm{nm}$ NDs with various ratios. The optimal mixture of trimeric $\mathrm{H} 7$ and NDs (designated as H7:ND) was screened using the Western blot and haemagglutination assays that are based on the binding capacity of trimeric $\mathrm{H} 7$ on the surface of NDs and the ability of trimeric $\mathrm{H} 7$ to agglutinate chicken red blood cells (RBCs), respectively. The successful conjugation of trimeric $\mathrm{H} 7$ onto the surface of NDs was analysed using a particle analyser, SDSPAGE, and Western blot. The trimeric H7 protein, NDs and the optimal mixture of $\mathrm{H7}$ :ND were injected in mice. Then, the immunogenicity induced by the optimal mixture of H7:ND in mice was compared to that of trimeric $\mathrm{H} 7$ as well as NDs only according to ELISA and Western blot.

\section{Methods \\ Production of the recombinant trimeric $\mathrm{H} 7$ protein Construction of the plant expression vector}

The DNA sequence that encodes amino acids (aa) 2-560 of Haemagglutinin subtype 7 (H7) of Influenza Antigen A/Anhui/1/2013 (UniProt Accession A0A0K1LFL0) was optimized for expression in tobacco plants, synthesized commercially (GeneCust Europe, Luxembourg) and provided in pUC57 vectors (designated as pUC57H7). The H5 gene in pRTRA-35S-LeB4SP-H5-pII-Hiscmyc-KDEL [19] was replaced with the synthesized DNA sequence that encodes ectodomain H7 (aa 17-520) to generate expression cassettes (pRTRA-35S-LeB4SP-H7pII-His-cmyc-KDEL) under the control of the CaMV $35 \mathrm{~S}$ 
promoter. The expression cassette in the pRTRA vector (shown in Fig. 1) was sub-cloned via the HindIII cleavage into the shuttle vector pCB301-Kan. The pCB301-H7-pII shuttle vectors were introduced into the Agrobacterium pGV2206 strain.

\section{Transient expression}

Agrobacterium infiltration for expressing recombinant proteins was described by Phan et al. [20]. Bacteria that harbour the shuttle vectors pCB301-H7-pII and HcPro vector were suspended in an infiltration buffer $[10 \mathrm{mM}$ 2-(N-morpholino)ethanesulfonic acid (MES), $10 \mathrm{mM}$ $\mathrm{MgSO}_{4}, \mathrm{pH}$ 5.6]. N. benthamiana plants (6-8 weeks old) were infiltrated by completely submerging each plant in an Agrobacterium-containing cup standing inside a desiccator and applying a partial vacuum for $2 \mathrm{~min}$. Next, the plants were kept in a greenhouse at $21^{\circ} \mathrm{C}, 16 \mathrm{~h}$ of light $/ 8 \mathrm{~h}$ of dark for 6 days, and then leaf samples were harvested and stored at $-80^{\circ} \mathrm{C}$.

\section{Protein purification via immobilized metal affinity chromatography (IMAC)}

Six days after vacuum infiltration of Agrobacterium, the leaf samples were harvested, treated in liquid nitrogen and homogenized using a commercial blender. Total protein was extracted in a Tris buffer $(50 \mathrm{mM}$ Tris- $\mathrm{HCl}, \mathrm{pH}$ 8.0). The extract was clarified via centrifugation twice at $75,465 \times g, 30 \mathrm{~min}, 4{ }^{\circ} \mathrm{C}$. The clear extract was mixed with a Ni-NTA agarose resin that was previously washed twice with water and once with a Tris buffer. After mixing at $4{ }^{\circ} \mathrm{C}$ for $30 \mathrm{~min}$, the mixture was applied to a chromatography column. Thereafter, the column was washed two times with a washing buffer $\left(50 \mathrm{mM} \mathrm{NaH} \mathrm{PO}_{4}\right.$, $300 \mathrm{mM} \mathrm{NaCl}, 30 \mathrm{mM}$ imidazole, $\mathrm{pH}$ 8.0). Then, recombinant protein was eluted from the column with an elution buffer $\left(50 \mathrm{mM} \mathrm{NaH}_{2} \mathrm{PO}_{4}, 300 \mathrm{mM} \mathrm{NaCl}, 250 \mathrm{mM}\right.$ imidazole, $\mathrm{pH}$ 8.0), put into dialysis bags, concentrated in PEG 6000, and dialyzed against PBS $(137 \mathrm{mM} \mathrm{NaCl}$,

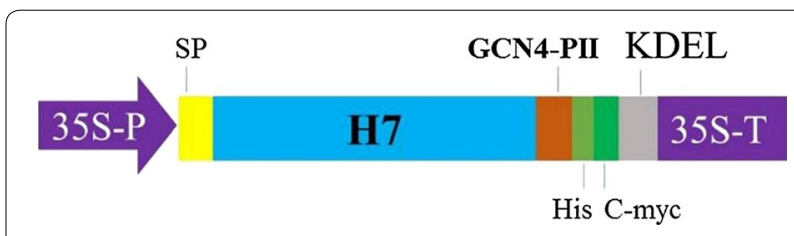

Fig. 1 Construct for expression of trimeric Haemagglutinin in plants. $\mathrm{H} 7$ was expressed in tobacco leaves under the control of the CaMV $35 \mathrm{~S}$ promoter. $\mathrm{H} 7$ was fused with trimeric motif GCN4-pll to form H7-pll. Recombinant H7 contained His and c-myc tags for affinity chromatography purification and Western blotting, respectively. The LeB4 signal peptide and KDEL motif were used to ensure ER retention. 35S-P: CaMV 35 S promoter; SP: legumin B4 signal peptide; $\mathrm{H7}$ : haemagglutinin A/H7N9; GCN4-pll: trimeric motif; His: His-tag; 35S-T: CaMV 35 S terminator
$2.7 \mathrm{mM} \mathrm{KCl}, 10 \mathrm{mM} \mathrm{Na}_{2} \mathrm{HPO}_{4}, 1.8 \mathrm{mM} \mathrm{KH}_{2} \mathrm{PO}_{4}, \mathrm{pH}$ 7.4) at $4{ }^{\circ} \mathrm{C}$ overnight.

\section{Cross-linking reaction}

To determine the multimeric state of the purified H7-pII protein, a cross-linking reaction was performed following the method described by Weldon et al. [28]. Briefly, $1 \mu \mathrm{g}$ of recombinant proteins was mixed with Bis[sulfosuccinimidyl]suberate (BS3) to a $5 \mathrm{mM}$ final concentration and incubated for $30 \mathrm{~min}$ at room temperature. The crosslinking reaction was stopped by adding $1 \mathrm{M}$ Tris $-\mathrm{HCl} \mathrm{pH} 8.0$ to a final concentration of $50 \mathrm{mM}$ and incubated for $15 \mathrm{~min}$ at room temperature. After cross-linking, the proteins were separated on a $4-10 \%$ SDS-PAGE under reducing conditions, blotted and analysed via Western blot using the above mentioned anti-cmyc monoclonal antibody.

\section{Production of surface-oxidized NDs}

Diamond powder (Diamond Innovations, USA) was surface-functionalized with oxygen containing groups via a harsh treatment in a strong oxidative acid mixture (3 volume of $\mathrm{H}_{2} \mathrm{SO}_{4}: 1$ volume of $\mathrm{HNO}_{3}$ ) under microwave heating $\left(\sim 100{ }^{\circ} \mathrm{C}\right)$ as described in a previous publication [13]. The treatment is conducted in a microwave reactor (100 W, Model Discover, CEM) for $3 \mathrm{~h}$. At the end of the microwave heating, precaution was carefully taken to ensure that the residual strong acids are diluted prior collection of the NDs. For safe operation, the microwave reactor is placed in a chemical fume-hood to protect the operator from $\mathrm{NO}_{2}$ exposure.

\section{Synthesis of the H7-ND complexes}

Oxidative ND particles are first thoroughly re-suspended in DI- $\mathrm{H}_{2} \mathrm{O}$ with the assistance of sonication at the concentration of $10 \mathrm{mg} / \mathrm{mL}$. To find the best conditions for maintaining the activity of protein samples as well as to obtain the good re-suspending nanoconjugates after protein coatings, various $\mathrm{H} 7: \mathrm{ND}$ ratios $(\mathrm{w} / \mathrm{w})$ of $1: 1,1: 3,1: 7$, $1: 9,1: 12$, and $1: 15$ were tested in different buffers such as $1 \times$ PBS and DI- $\mathrm{H}_{2} \mathrm{O}$. Sonication for $1 \mathrm{~h}$ was applied during coating.

\section{H7:ND characterization}

\section{Size and Zeta-potential measurements}

Size distributions and Zeta-potentials of NDs before and after protein coatings were measured using a particle analyser (Delsa ${ }^{\circledR}$ NanoC, Backman Coulter, USA). For size distribution and Zeta potential measurements, bare-NDs and protein-coated FNDs are re-suspended in $\mathrm{DI}-\mathrm{H}_{2} \mathrm{O}$ at the concentration of $50 \mu \mathrm{g} / \mathrm{mL}$. To evaluate the aggregating tendency of the protein-coated ND complexes in salt 
buffers, the samples were re-suspended in $1 \times$ PBS, followed by particle size measurements.

\section{SDS-PAGE and Western blot of protein-coated NDs}

The protein-coated ND particles were first washed twice with deionized water to remove loosely bound moieties, such as salts or excessive protein molecules, before elution with $20 \mu \mathrm{L}$ of an SDS-PAGE loading buffer (3\% SDS, $1.5 \%$ DTT, $0.1 \%$ bromophenol blue, $0.5 \mathrm{M}$ Tris- $\mathrm{HCl} \mathrm{pH}$ $6.8,10 \%$ glycerol). Only the supernatants containing proteins were loaded onto the gels. Casting and running of protein gels was performed according to Laemmli using BioRad's Miniprotean II. Western blots were performed following the protocol described by Gahrtz et al. [4]. ImageJ was then used to analyse the Western blot result based on the intensity of the $\mathrm{H} 7$ protein band.

\section{Transmission electron microscopy (TEM) analysis}

The shape and surface properties of surface-oxidized NDs, H7:ND complexes were further characterized via TEM images. ND and H7:ND complexes were re-suspended in DI- $\mathrm{H}_{2} \mathrm{O}$ at a concentration of $1 \mathrm{mg} / \mathrm{mL}$. Then, the particles in solution are coated onto the TEM plate for image acquisition.

\section{Haemagglutination assay}

Haemagglutination assays were performed following the World Organization for Animal Health recommendation [30]. In detail, $50 \mu \mathrm{L}$ of PBS were added into all wells of a plastic V-bottom microtiter plate. Next, $50 \mu \mathrm{L}$ of antigen was added into the first well of a plastic V-bottom microtiter plate. A 2-fold serial dilution was made across the entire row. In total, $50 \mu \mathrm{L}$ of the last dilution was discarded. Furthermore, $50 \mu \mathrm{l}$ of $1 \%$ chicken RBCs was added to each well. After incubating the plates at $25^{\circ} \mathrm{C}$ for $30 \mathrm{~min}$, the results were read. The endpoint dilution that causes complete haemagglutination was defined as one haemagglutination unit (HAU).

\section{Mouse experiment}

The 6-8-week-old female BALB/C mice (five per group) were immunized using subcutaneous route on a schedule of 1, 14, 28 days with $5 \mu \mathrm{g}$ of purified H7-pII trimer (group 1), a mixture of $5 \mu \mathrm{g}$ of purified H7-pII trimer and $60 \mu \mathrm{g}$ of NDs [at a ratio of 1:12 (w/w, group 2]. In the control group, mice were injected with a mixture of PBS and $60 \mu \mathrm{g}$ of NDs (group 3). The antigens were formulated with complete Freund's adjuvant in the first immunization and with incomplete Freund's adjuvant in the booster immunizations. One week after the 2 nd and $3 \mathrm{rd}$ immunization, the mice were bled via the retro-orbital sinus. Mouse sera were collected individually for ELISA tests and Western blot.

\section{ELISA}

For testing mouse sera, microtiter plates (ImmunoPlate Maxisorp, Nalgen Nunc International, Roskilde, Denmark) were coated with $100 \mu \mathrm{L}$ of $50 \mathrm{ng}$ H7 (Influenza Antigen A/Anhui/1/2013 (H7N9), NIBSC) in PBS $\left(100 \mathrm{mM} \mathrm{NaCl}, 32 \mathrm{mM} \mathrm{Na}_{2} \mathrm{HPO}_{4}, 17 \mathrm{mM} \mathrm{Na}_{2} \mathrm{HPO}_{4}, \mathrm{pH}\right.$ 7.2) and incubated overnight. After blocking with 3\% $(\mathrm{w} / \mathrm{v})$ bovine serum albumin (BSA), 0.05\% (v/v) Tween20 in PBS (PBST) for $2 \mathrm{~h}, 100 \mu \mathrm{L}$ of the specific mouse sera dilution [5000 times in $1 \%(\mathrm{w} / \mathrm{v}) \mathrm{BSA}$ in PBST] and an anti H7N9 haemagglutinin/HA monoclonal mouse antibody (SinoBiological InC.) at concentrations of 0.5, 0.75, $1,1.25,2.5,5,12.5,25,50,100,150 \mu \mathrm{g} / \mathrm{mL}$ was applied on each ELISA plate and incubated at $25{ }^{\circ} \mathrm{C}$ for $1 \mathrm{~h}$. Each serum dilution was measured in triplicate. The plates were washed 5 times with PBST, followed by the addition of $100 \mu \mathrm{l}$ of a goat anti-mouse IgG conjugate horseradish peroxidase (HRP) dilution (2000 times in $1 \%(\mathrm{w} / \mathrm{v}) \mathrm{BSA}$ in PBST and then incubated at $25^{\circ} \mathrm{C}$ for $1 \mathrm{~h}$. The enzymatic substrate, $1-$ Step $^{\mathrm{TM}}$ Ultra TMB-ELISA Substrate Solution (Thermo Fisher Scientific, Lithuania) was added. After $20 \mathrm{~min}$ of incubation, the reaction was stopped via $1 \mathrm{M} \mathrm{HCl}$. All mouse sera were applied at the same ELISA conditions. The absorbance signal was measured at $450 \mathrm{~nm}$. The ELISA values of all mouse sera were normalised by use of a monoclonal mouse standard H7N9 haemagglutinin/HA antibody (SinoBiological Inc.). A standard curve was built using the OD450 values corresponding to different concentrations of this antibody. Control values for BSA at the solid phase were subtracted. The amounts of specific anti H7N9 haemagglutinin/HA antibodies in the sera were calculated using this standard curve.

\section{SDS-PAGE and Western blot}

Proteins were separated in a $12 \%$ SDS-PAGE gel and transferred to a PVDF membrane (Millipore) via a semidry Fast Blotter (Thermo Scientific). After blocking with a $5 \%(\mathrm{w} / \mathrm{v})$ fat-free milk powder dissolved in a PBS buffer $\left(137 \mathrm{mM} \mathrm{NaCl}, 2.7 \mathrm{mM} \mathrm{KCl}, 10 \mathrm{mM} \mathrm{Na}{ }_{2} \mathrm{HPO}_{4}, 1.8 \mathrm{mM}\right.$ $\mathrm{KH}_{2} \mathrm{PO}_{4}, \mathrm{pH}$ 7.4), the membrane was incubated for $2 \mathrm{~h}$ at room temperature with the addition of a 1:50 dilution of monoclonal anti-c-myc antibody and later with HRP conjugated goat anti-mouse IgG secondary antibody at a 1:2000 dilution.

To detect the H7-specific IgG mouse antibodies, each $100 \mathrm{ng}$ of purified H7 (Influenza Antigen A/ Anhui/1/2013 (H7N9), NIBSC) was loaded on 7 lanes of one SDS-PAGE gel. The proteins were separated according to their molecular weight and transferred to a PVDF membrane (Millipore) via a semidry Fast Blotter (Thermo Fisher Scientific, USA). After 2 h blocking with a $5 \%(\mathrm{w} / \mathrm{v})$ fat-free milk powder dissolved in a PBS 
buffer (137 mM NaCl, $2.7 \mathrm{mM} \mathrm{KCl,} 10 \mathrm{mM} \mathrm{Na}_{2} \mathrm{HPO}_{4}$, $1.8 \mathrm{mM} \mathrm{KH}_{2} \mathrm{PO}_{4}, \mathrm{pH}$ 7.4), 7 lanes of the membrane were separated via cutting. Then, the single stripes were incubated for $2 \mathrm{~h}$ at room temperature with a 1:500 dilution of mixture of five mice sera of each group (group 1, group 2 and group 3). Anti-mouse H7N9 Haemagglutinin/HA antibody (SinoBiological InC., China) was used as a positive control (P). Next, the membranes were incubated for $1 \mathrm{~h}$ at room temperature with the addition of a 1:2000 dilution of an HRP conjugated goat anti-mouse IgG secondary antibody.

Specific signals were visualized by incubating membranes in dark with 3,3-diaminobenzidine (DAB, Thermo Scientific Pierce) in $0.05 \mathrm{M}$ Tris- $\mathrm{HCl}$ and $0.04 \%$ hydrogen peroxide for $10 \mathrm{~min}$.

\section{Statistical analysis}

Statistical analyses for ELISA test were performed using t-test in the Sigma Plot software. The mean difference between sample data was compared and is presented as $\mathrm{X} \pm$ Standard deviation (SD). $\mathrm{P}$ values that are less than 0.05 were defined as significant difference.

\section{Results}

\section{Production and characterization of $\mathrm{H} 7 \mathrm{Haemagglutinin}$} Expression of influenza $\mathrm{H} 7 \mathrm{Haemagglutinin}$ in plants

To efficiently express $\mathrm{H} 7$ in plant cells, the sequence that encodes ectodomain (aa 17-520) of the Influenza Antigen A/Anhui/1/2013 strain was synthesized with optimized codons and cloned in an expression cassette (Fig. 1). The $\mathrm{H} 7$ protein was recombinantly expressed as a fusion with a trimeric motif (GCN4-pII) under the control of CaMV 35S. The recombinant $\mathrm{H} 7$ protein contained the c-myc tag for downstream detection via Western blot, a His tag for purification via IMAC and the KDEL motif at the $\mathrm{C}$-terminal end to retain protein in the endoplasmic reticulum (ER).

The functionality of the binary vector containing H7-pII was validated via transient expression in $N$. benthamiana leaves, determined via SDS-PAGE under reducing conditions, and Western blot using an anti-cmyc monoclonal antibody (Fig. 2a). Western blot analysis indicates that recombinant H7-pII was successfully expressed in plants. The apparent molecular weight shown in Fig. 2a is higher than the expected sizes predicted from the polypeptide sequence of H7. This can be explained by the fact that glycosylation influences the running behaviour during the electrophoretic separation.

\section{Purification and characterizations of recombinant $\mathrm{H7}$ expressed in $N$. benthamiana leaves}

To obtain recombinant $\mathrm{H} 7$ for further experiments, the H7-pII protein containing a C-terminal $6 \times$ histidine tag was purified from plant leaves via IMAC. The samples from each step of the purification procedure were collected and analysed via SDS-PAGE and Western blot using a monoclonal-anti c-myc antibody (Fig. 2b). Western blot analysis reveals that one band corresponds to H7-pII in the elution fraction. These results indicate that the H7-pII protein was highly enriched from tobacco plant leaves and successfully purified.

After purification of the H7-pII protein, the oligomeric state of this protein was determined via a cross-linking reaction using a BS3 chemical, a water-soluble and

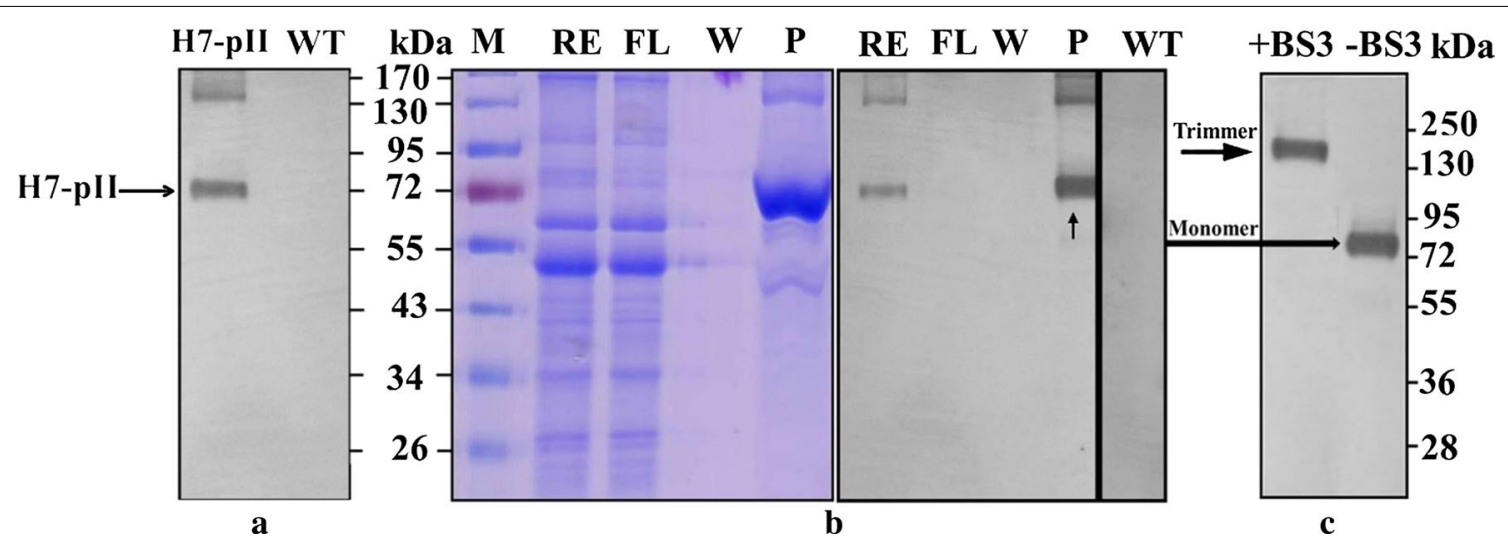

Fig. 2 Purification and characterizations of recombinant trimeric $\mathrm{H} 7$ expressed in N. benthamiana leaves. a Recombinant H7-pll produced from agro-infiltrated tobacco leaves and detected by Western blot: H7-pll: $20 \mu \mathrm{g}$ of total soluble protein extracts from tobacco leaves; Wt: wild type used as the negative control. b Purification of H7-pll from total soluble protein extracts using IMAC: RE raw extract, FT flow through, W wash fraction, $P$ purified fraction in SDS-PAGE (Left) and H7-pll immunological detection via anti-c-myc monoclonal antibody (Right); WT wild type N. benthamiana; M protein marker (Right). c Detection of oligomeric states of H7-pll via the cross-linking reaction: (-) and (+) BS3: indicate a cross-linker bis(sulfosuccinimidyl)substrate (BS3) with 0 and $5 \mathrm{mM}$ final concentration, respectively. The resulting products were separated via the $4-10 \%$ gradient SDS-PAGE under reducing conditions, blotted and detected via anti-c-myc monoclonal antibody 
homobifunctional cross-linker that reacts with primary amines of proteins to form stable amide bonds. When oligomeric proteins were exposed to BS3, cross-links between each subunit of the multimeric proteins are formed. This is a direct evidence for their close proximity. Following cross-linking, reaction products were separated on a gradient of $4-10 \%$ SDS-PAGE under reducing conditions, blotted and immune detected using an antic-myc monoclonal antibody. The immunoblot results in Fig. 2c revealed a band with a molecular weight of approximately $220 \mathrm{kDa}$ after $\mathrm{H} 7$-pII was cross-linked via BS3. This result indicates that H7-pII is an exclusively trimeric protein.

\section{Production and characterization of surface-oxidized NDs}

The size distribution and TEM analysis of NDs used in the present experiment are shown in Fig. 3. It is clearly observed that we have a mixture of ND particles with a wide range of sizes from $\sim 50$ to $\sim 500 \mathrm{~nm}$ in diameter (Fig. 3a). The size distribution of $\mathrm{NDs}$ in $\mathrm{H}_{2} \mathrm{O}$ suggested that more than two particles can from aggregates, and there may be a variation in size between different particles. Indeed, the TEM analysis illustrated on Fig. 3b shows both a single ND and an aggregate of 2 ND particles. In addition, we can see from the TEM images that the NDs are not round, and individual particles are very different in shape. It is also noted from Fig. 3a, that NDs can form a very bad aggregation in salt solutions such as $1 \times$ PBS.

In the study, we used NDs that were oxidized in a mixture of strong acids including $\mathrm{HNO}_{3}$ and $\mathrm{H}_{2} \mathrm{SO}_{4}$ at a volume ratio of 1:3. After the harsh acid treatment, NDs are decorated with oxygen-containing functional groups, such as carboxylic acids, and thus have a negatively charged surface.

\section{Synthesis and characterization of the H7:ND complexes Synthesis and physical characterization of the H7:ND complexes}

The H7:ND complexes were synthesized via a simple mixing of protein solution and ND suspension for $1 \mathrm{~h}$ under sonication. Different Protein/ND ratios (w/w) (1:1, $1: 3,1: 5,1: 7,1: 9,1: 12$ and 1:15) were tested to find the best synthetic condition. Figure 4 shows the changes in the size distribution of ND before and after coating with trimeric $\mathrm{H} 7$ protein at a $1: 1(\mathrm{w} / \mathrm{w})$ ratio. The proteincoated ND samples were re-suspended in both DI- $\mathrm{H}_{2} \mathrm{O}$ and $1 \times$ PBS for the particle size measurements. It can be clearly seen from Fig. 4a, b that ND particles increase in size to approximately $80 \mathrm{~nm}$ in diameter after protein coating. These results indicated that a significant amount of protein was conjugated onto the surface of ND particles. Comparing the size distribution of $\mathrm{H} 7: \mathrm{ND}$ and $\mathrm{ND}$ in $1 \times$ PBS also revealed that protein coating helps preventing fast aggregation of the nanoparticles in a physiological condition.

To further analyse the change in surface chemistry of ND after H7 coating, we measured Zeta-potential of NDs in comparison with the H7:ND complexes. We found that both types of particles have negatively charged surfaces. Furthermore, the change of Zeta-potential is from $\sim-45 \mathrm{mV}$ for ND to $\sim 38 \mathrm{mV}$ for H7:ND (Fig. 4c).

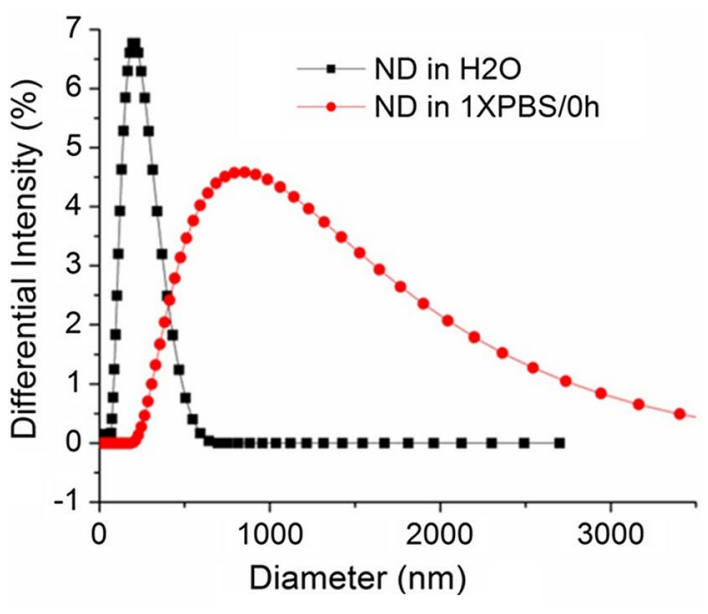

a

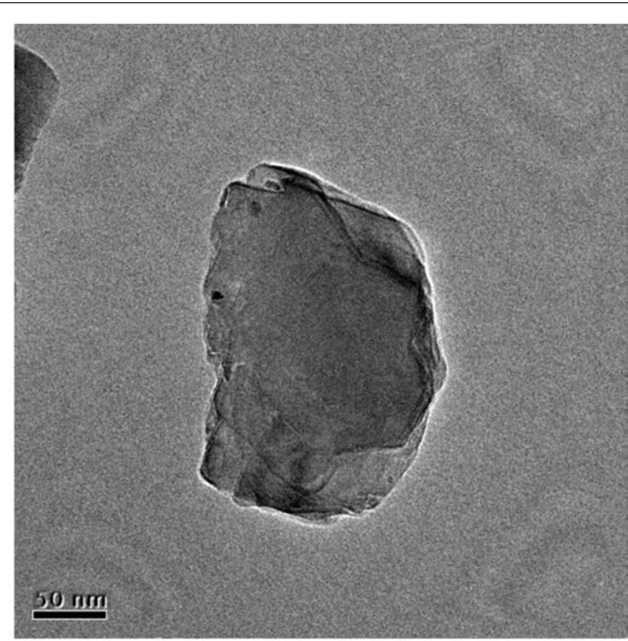

b

Fig. 3 Preparation and characterization of nanodiamonds. a Size distribution of re-suspended nanodiamonds in $\mathrm{H}_{2} \mathrm{O}$ and $1 \times$ PBS; $\mathbf{b}$ TEM image of nanodiamond resuspension in $\mathrm{H}_{2} \mathrm{O}$ 

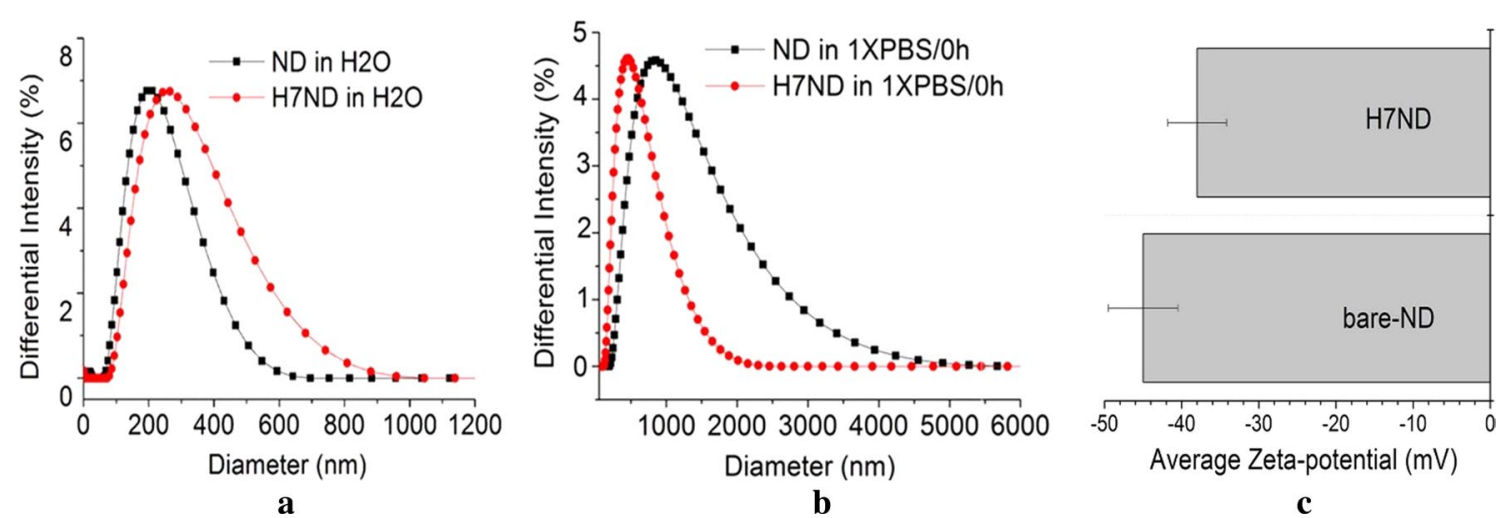

Fig. 4 Synthesis and physical characterization of H7-ND conjugates. The re-suspension of nanodiamond particles before protein coating (ND) and after coating with trimeric $\mathrm{H} 7$ protein (H7:ND): $\mathbf{a}$ in $\mathrm{H}_{2} \mathrm{O}$; b in $1 \times$ PBS; c Zeta-potential of $\mathrm{H7}$ : ND and ND

\section{Characterization and bio-functional screening of the optimal mixture of purified trimeric $\mathrm{H} 7$ and nanodiamonds}

To further prove the existence of trimeric $\mathrm{H} 7$ onto the surface of ND after protein coating, we analysed the H7:ND conjugates via SDS-PAGE and Western blot (Fig. 5a). Then, ImageJ was used to analyse the Western blot result based on the intensity of the $\mathrm{H} 7$ protein band. After the measurement, for the $\mathrm{H} 7: \mathrm{ND}$ ratio ranges of $1: 1-1: 12(\mathrm{w} / \mathrm{w})$, the binding capacity of trimeric $\mathrm{H} 7$ on the surface of NDs proportionally increased (from 20 to $82 \%$ ) with the amount of NDs present in the H7-ND complexes. However, when adding more NDs that correspond to the $H 7: N D$ ratio of $1: 15(w / w)$, the binding capacity of trimeric $\mathrm{H7}$ on the surface of NDs was not increased. This may explain that the binding capacity of trimeric $\mathrm{H7}$ on the surface of NDs was saturated.

The biological activity of the purified trimeric Haemagglutinin proteins after mixing with NDs was assessed using a haemagglutination assay. The results of haemagglutination assay are shown in Fig. 5b. These results indicate that the ability to agglutinate chicken RBCs increased using the mixture of trimeric $\mathrm{H} 7$ and more ND, which corresponds to the H7:ND ratios of 1:1-1:12 (w/w). This confirms that H7:ND retained its function of RBCs binding ability. The mixture of $\mathrm{H7}: \mathrm{ND}$ at the ratio of $1: 12(\mathrm{w} / \mathrm{w})$ exhibited the highest haemagglutination activity (HAU $=1024$ per $50 \mu \mathrm{L}$ of the mixture of $100 \mathrm{ng} /$

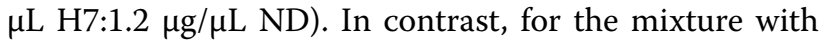
an H7:ND ratio of 1:15 (w/w), the HA titer was decreased $(\mathrm{HAU}=512)$ due to an unknown reason. The PBS:ND at the ratio of 1:15 (w/w) (not other PBS:ND ratios) agglutinated chicken RBCs at HA titer of 4 . This means that at a certain amount of ND, it can bind to receptors on the surface of RBCs to create the network with RBCs. We suggest a hypothesis that ND may act as a non-competitive/ competitive inhibitor of $\mathrm{H} 7$ if too much NDs are present in the mixture of $\mathrm{H} 7: \mathrm{ND}$ (H7:ND ratio of 1:15, w/w). We observed that the free trimeric H7 (50 $\mu \mathrm{L}$ of $100 \mathrm{ng}$ / $\mu \mathrm{L}=5 \mu \mathrm{g}$ ) was able to agglutinate RBCs at HA titer of 2, which is 512 -folds less than HA titer of the H7:ND mixture at a ratio $(\mathrm{w} / \mathrm{w})$ of $1: 12$. Therefore, these results indicate that the optimal $\mathrm{H} 7: \mathrm{ND}$ ratio $(\mathrm{w} / \mathrm{w})$ is $1: 12$.

\section{H7:ND elicited stronger H7 specific-IgG antibody responses than trimeric $\mathrm{H} 7$ shown by ELISA and Western blot}

Trimeric H7 (5 $\mu \mathrm{g}$, group 1) and a mixture of trimeric $\mathrm{H} 7$ with NDs in a formulation containing 5 and $60 \mu \mathrm{g}$, respectively corresponds to the ratio of 1:12 (w/w, group $2)$ as well as ND (60 $\mu$ g, group 3) separately diluted in PBS were used for immunization in mice (Fig. 6a). H7 specific IgG antibody responses in the sera of immunized mice were evaluated via ELISA and Western blot.

The measurement of $\mathrm{H} 7$ specific IgG amount in mouse sera via ELISA is shown in Fig. 6b. Each serum was measured in triplicate. All sera were diluted 1:5000. A monoclonal mouse anti- H7N9 haemagglutinin/HA antibody was applied as a standard. Specific immune responses were measured after 1 and 2 booster immunizations with H7 (group 1), H7:ND (group 2) and PBS:ND (group 3 ). The control values for BSA as an antigen at the solid phase in the ELISA were subtracted. The responses were recalculated according the standard values as $\mu \mathrm{g} /$ $\mathrm{mL}$ anti H7N9 antibody in the sera (see Materials and Methods). The mean values including the standard deviations as bars are represented in each dot. The square means for every group (5 individuals) were determined and compared by the t-test (Fig. 6b). The ELISA results showed that there was a statistically significant difference between mouse group 1 and group $2(\mathrm{P}<0.05)$. Notably, after the 2nd and 3rd immunization, the ELISA results in Fig. 6b illustrate that H7:ND (group 2) induced higher 


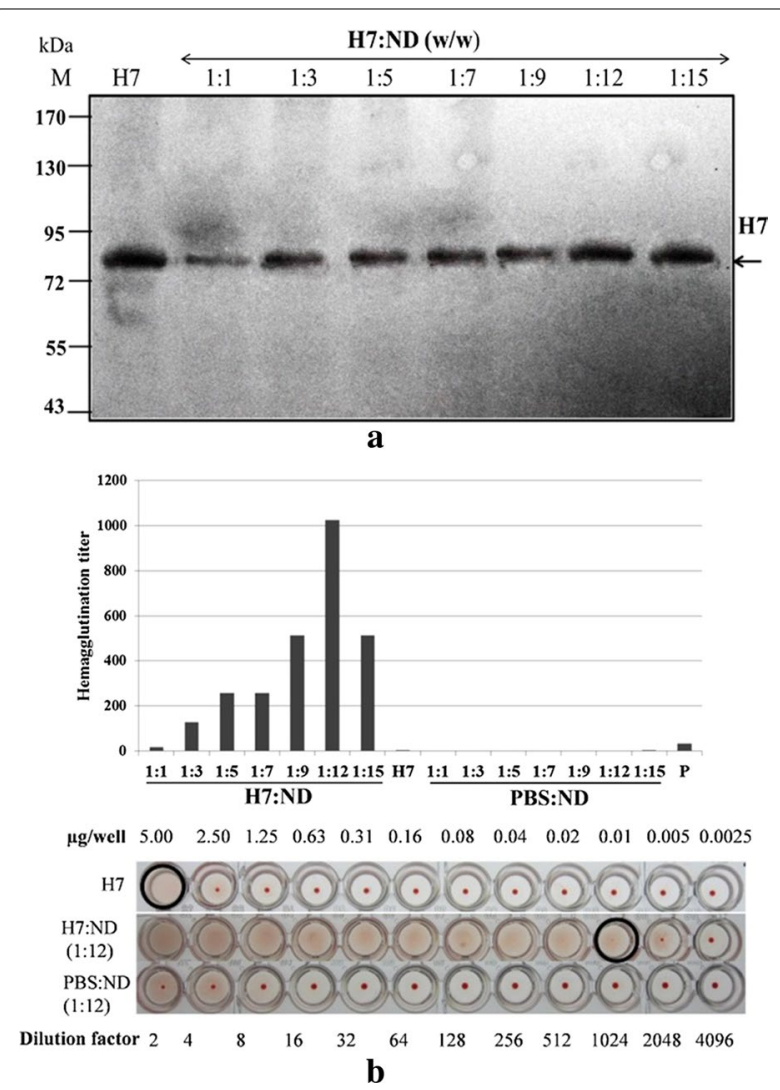

Fig. 5 Western blot and bio-functional screening of different H7-ND conjugates. a Western blotting analysis confirms the conjugation of trimeric $\mathrm{H} 7$ with $\mathrm{ND}$ at different ratios. Trimeric $\mathrm{H} 7(100 \mathrm{ng} / \mu \mathrm{L})$ was used for combining with NDs at different ratios (1:1, 1:3, 1:5, 1:7, 1:9, $1: 12,1: 15, \mathrm{w} / \mathrm{w})$. After mixing, the resulting products were washed in water and diluted in PBS. The same volume of H7 $(2.5 \mu \mathrm{g})$ and all mixtures of $\mathrm{H7}$ :ND separated by $10 \%$ SDS-PAGE were blotted and detected with anti-c-myc monoclonal antibody followed by horseradish peroxidase-linked sheep anti-mouse $\lg \mathrm{G}$ as a secondary antibody. b Bio-functional characterization of trimeric $\mathrm{H} 7$ and the mixture of trimeric $\mathrm{H} 7$ and $\mathrm{ND}$ via a haemagglutination assay. Trimeric $\mathrm{H7}(100 \mathrm{ng} / \mu \mathrm{L})$ was used for combining with NDs at different ratios $(1: 1,1: 3,1: 5,1: 7,1: 9,1: 12,1: 15$, w/w). P: inactivated virus $A$ / Hatay/2004/(H5N1) strain

amounts of $\mathrm{H} 7$ specific IgG antibodies in mouse sera (over 15.4- and 1.9-fold), respectively, than trimeric H7 did (group 1). In contrast, no H7 specific IgG antibodies were detected in mouse sera produced by immunization with PBS:ND (group 3).

Five mice sera collected after the 2nd and 3rd immunization of each group (H7:ND, H7 and PBS:ND) were mixed and used as a primary antibody for detecting purified H7. The Western blots in Fig. 6c indicate that stronger H7-specific IgG antibody responses were induced in mice vaccinated with H7:ND (group 2) than trimeric $\mathrm{H} 7$ (group 1). The $\mathrm{H} 7$ specific antibody responses were strongly increased after the $3 \mathrm{rd}$ immunization shown by Western blot analysis. In contrast, there was no $\mathrm{H} 7$ specific IgG antibody response induced in mice control group vaccinated with PBS:ND (group 3).

\section{Discussion}

The H7-VLPs vaccine has been shown to elicit highly efficient and protective immune responses against the H7N9 influenza virus because of high molecular weight of $\mathrm{H} 7$ formation, which was formed by its self-assembly [9, $21,23]$. According to previous studies on the efficacy of neutralizing antibodies elicited by recombinant HA proteins from avian $\mathrm{H} 5 \mathrm{~N} 1$ influenza virus, a high-molecularweight $\mathrm{HA}$ oligomer elicited the strongest neutralizing antibody response, followed by the HA trimer, while the monomer showed minimal efficacy [27]. For generating HA oligomers, it seems that recombinant HA fragments themselves cannot easily form functional, conformational trimeric or oligomeric structures, while the formation of these functional molecules of HA may be influenced by the addition of further sequences $[3,13,20,28]$.

In the present study, the trimeric $\mathrm{H} 7$ protein was formed by fusing $\mathrm{H} 7$ with a trimeric GCN4pII heptads repeat sequence derived from a wild-type dimeric GCN4 repeat found in Saccharomyces cerevisiae [7, 28]. To generate oligomeric $\mathrm{H} 7$ as a synthetic H7-VLP formation, trimeric $\mathrm{H7}$ was physically mixed with a mixture of NDs in a wide range of sizes from $\sim 50$ to $\sim 500 \mathrm{~nm}$ in diameter in optimized ratios. In the current study, we have shown that a facile and successful conjugation of $\mathrm{H} 7$ onto the surface of NDs can be obtained by simply mixing them together in DI- $\mathrm{H}_{2} \mathrm{O}$. Characterization of the H7:ND complexes via size measurements, SDS-PAGE, Westernblot, and haemagglutination assay showed that recombinant proteins are non-covalently conjugated onto ND surface, and the activity of protein is well preserved after conjugation. In the previous study, it was shown that $\mathrm{rH} 7$ isolated from Sf9 cells represents high-molecular-weight VLP nanoparticles of approximately $20 \mathrm{~nm}$ that are likely comprised of 3-4 HA trimers, and that data suggest that the majority of $\mathrm{H} 7$ forms oligomeric VLP, which may be important for immunogenicity [23]. In the present study, the change in surface chemistry of NDs after trimeric $\mathrm{H} 7$ coating is not prominent since the Zeta-potential of ND and H7:ND was $\sim-45$ and $\sim-38 \mathrm{mV}$, respectively. Since H7 is a glycoprotein, it is more likely that the protein does not interact with NDs through its glycanexpressing regions. After protein conjugation onto the ND surface, its glycans with negatively charged molecules are exposed to water. Because ND is a carbon-based nanoparticle, it likely interacts with the protein through hydrophobic forces as also observed for other membrane proteins [17]. Thus, the glycan expression domains of H7, 

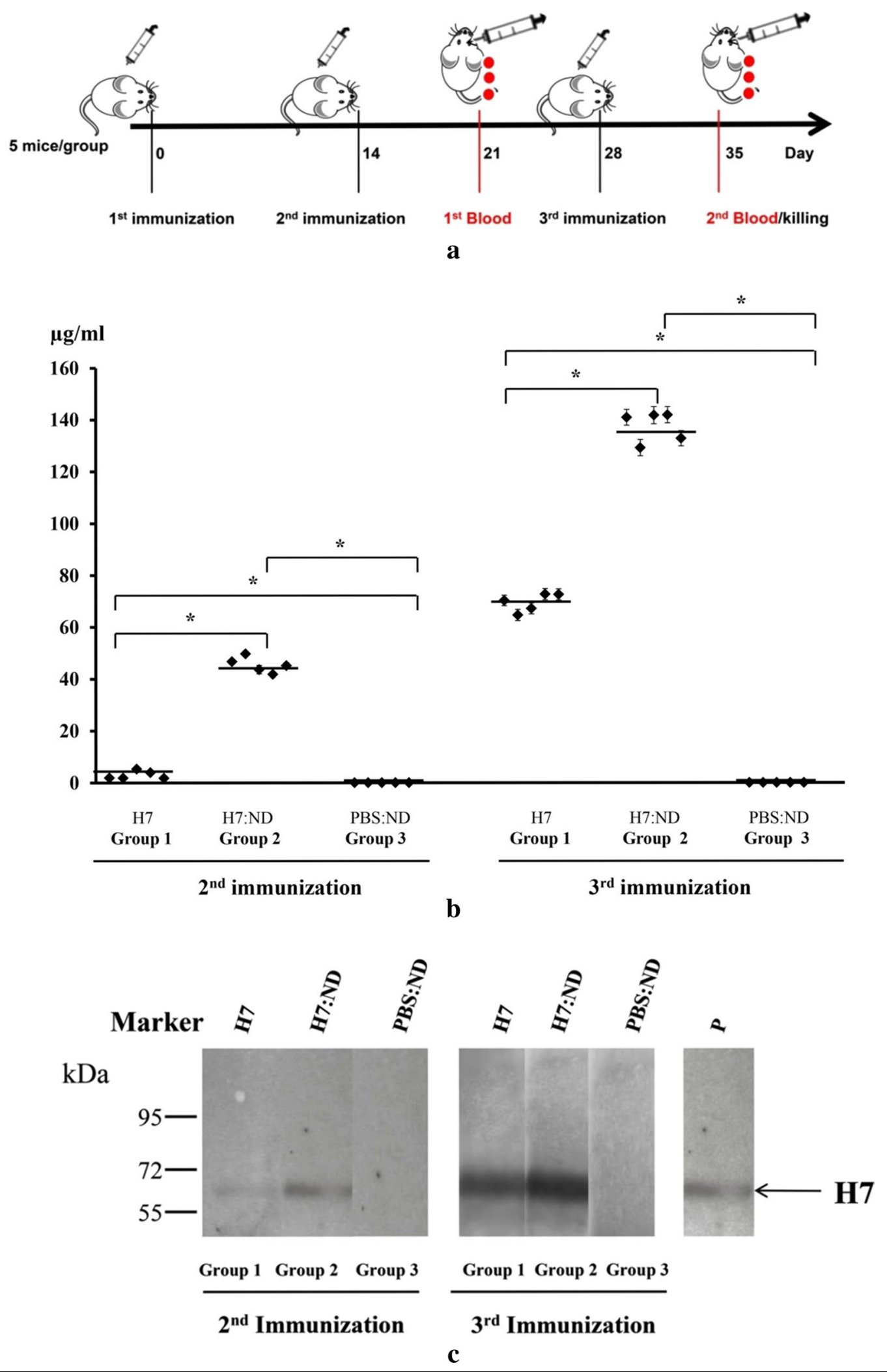
(See figure on previous page.)

Fig. 6 Immunopotentiation following immunization with an $\mathrm{H} 7: \mathrm{ND}(1 / 12, \mathrm{w} / \mathrm{w})$ conjugate. a Immunization scheme in mice. b Measurement of $\mathrm{H} 7$ specific IgG amount in mouse sera via ELISA. In total, 50 ng of purified H7 [Influenza antigen A/Anhui/1/2013 (H7N9), NIBSC] per well were coated at the plate. The sera were diluted 1:5000 and a monoclonal mouse anti- H7N9 haemagglutinin/HA antibody (SinoBiological InC.) at concentrations of $0.5,0.75,1,1.25,2.5,5,12.5,25,50,100,150 \mu \mathrm{g} / \mathrm{mL}$ was applied as a standard, then analysed via ELISA. Specific immune responses were measured at $450 \mathrm{~nm}$ after 1 and 2 booster immunizations with H7 (group 1), H7:ND (group 2) and PBS:ND (group 3). The responses were recalculated according the standard values as $\mu \mathrm{g} / \mathrm{mL}$ anti H7N9 antibody in the sera. The BSA background was subtracted. A standard curve was built by the help of OD450 values corresponding to known amounts of H7N9 haemagglutinin/HA antibody. The amount of H7 specific lgG antibody in mouse sera was measured via the standard curve. Statistical analyses were performed using the t-test (SigmaPlot) and are presented. A single dot indicates the value of a single mouse serum. SD was included on a single dot that corresponds to an ELISA data variation of a single mouse serum with three replications. The bars indicate the average value of the test groups. $\mathrm{P}<0.05$ was defined as a statistically significant difference. $\mathbf{c}$ Detection of H7-specific IgG antibodies via a Western blot. Sera from five mice from each group (against H7, H7:ND and PBS:ND as a negative control) were mixed, diluted 500 times and used as a primary antibody for detecting $100 \mathrm{ng}$ of purified H7 [Influenza Antigen A/Anhui/1/2013 (H7N9), NIBSC]. Anti-mouse H7N9 haemagglutinin/HA antibody (SinoBiological InC.) was used as a primary antibody (positive control: P). HRP-linked goat anti-mouse IgG was used as a secondary antibody

which are mostly the epitopes of protein, are preserved and allow recognition by immune cells.

The optimal mixture of trimeric H7 and ND was further screened by Western blot and haemagglutination assay. Following removal of free proteins, antigen-loaded particles were recovered. Our data suggest that the mixture of $\mathrm{H} 7: \mathrm{ND}$ at a ratio of 1:12 (w/w) exhibited the highest binding capacity of trimeric $\mathrm{H} 7$ on the surface of NDs (82\%), and agglutinated chicken RBCs at HA titer of 1024, which is 512-folds higher HA titer than its free trimeric H7. Notably, our synthetic H7-VLP exhibited a haemagglutination activity at a minimum total protein amount of $0.01 \mu \mathrm{g}$ (Fig. 5b), which is lower than the minimum total protein amount of H7 VLP exhibiting haemagglutination activity from previous studies of $\mathrm{Hu}$ et al. [9] and Pushko et al. [23] of 0.098 and $0.039 \mu \mathrm{g}$, respectively. In contrast, in the present study, the free trimeric $\mathrm{H} 7$ agglutinated chicken RBCs at a minimum amount of total protein of $5 \mu \mathrm{g}$. These data suggest that ND presents a potential effect related to bio-function of H7 VLP shown in haemagglutination activity.

As expected, immunization with a physical mixture of H7:ND, which contains $5 \mu \mathrm{g}$ of $\mathrm{H} 7$ and $60 \mu \mathrm{g}$ of ND in formulation, elicited significantly higher H7-specific IgG antibodies over free trimeric $\mathrm{H} 7$ protein (shown in Western blot and ELISA result), which suggests a potential effect inherent to NDs. H7:ND may form oligomeric $\mathrm{H} 7$ as synthetic H7-VLPs that enhance $\mathrm{H} 7$ presentation and immune processing and are transported to draining lymph nodes for stronger H7-specific IgG immune responses. In a previous study, synthetic VLPs were prepared by mixing $100 \mathrm{~nm}$ gold nanoparticles and a spike protein [1]. Compared with inoculation with free proteins, vaccination with synthetic VLP showed enhanced lymphatic antigen delivery, stronger antibody titers, increased splenic T-cell response, and reduced infection-associated symptoms in an avian model of corona virus infection [1]. VLPs can act as adjuvants by carrying peptide sequences into antigen presenting cells and thus enhancing antigen processing pathways [25]. Surfacemodified diamond nanoparticles can conformational stabilize proteins/peptides. NDs also provide a high degree of surface exposure to protein antigens. The elicitation of a strong and specific immune response as we observed can thus be explained by an adjuvant effect [15].

\section{Conclusions}

In summary, synthetic H7-VLP was formed by mixing trimeric $\mathrm{H} 7$ antigen with synthetic NDs in optimized ratio and induced the assembly of a virus-like nanoparticle with viral trimeric $\mathrm{H} 7$ antigens covering the particulate core. Our result demonstrated the successful preparation of synthetic VLP via physical mixing of NDs with trimeric H7. Vaccination with the physical mixture of $5 \mu \mathrm{g}$ of trimeric $\mathrm{H} 7$ protein and $60 \mu \mathrm{g}$ of NDs elicited stronger $\mathrm{H} 7$ specific-IgG immune responses than free trimeric $\mathrm{H} 7$ protein. NDs have the potential to improve vaccine efficacy. NDs will continue to address challenges remaining in immunology and provide innovative strategies that can be broadly applied for the development of different vaccines in the future.

\section{Abbreviations \\ DI- $\mathrm{H}_{2} \mathrm{O}$ : deionized $\mathrm{H}_{2} \mathrm{O}$; ER: endoplasmic reticulum; $\mathrm{H}$ 7-pll (trimeric $\mathrm{H} 7$ ): $\mathrm{H} 7$ fused GCN4-pll motif protein; HA: haemagglutinin; HAU: haemagglutination unit; HRP: horseradish peroxidase; H7:ND: mixture of trimeric $\mathrm{H7}$ and ND; IMAC: immobilized metal ion chromatography; ND: nanodiamond; RBCs: red blood cells; TEM: transmission electron microscopy; VLP: virus-like particles.}

\section{Authors' contributions}

HHC and NBP designed the research. NTL constructed vectors. TTL performed transient expression. TTH purified protein and performed the cross-linking reaction. MDP and HCC prepared and characterized nanodiamonds. MDP, NBP, TTH and GTN designed, synthesized, and characterized the H7-ND conjugates. TTH and GTN performed ELISA and Western Blots. NBP, TTH, GTN and MDP performed calculation, all data analysis and wrote the manuscript. UC and $\mathrm{HHC}$ revised the manuscript. HHC is the corresponding author and holds all the responsibilities related to this manuscript. All authors read and approved the final manuscript. 


\begin{abstract}
Author details
${ }^{1}$ Institute of Biotechnology, Vietnam Academy of Science and Technology, $\mathrm{Ha}$ Noi, Vietnam. ${ }^{2}$ Graduate University of Science and Technology, Vietnam Academy of Science and Technology, Ha Noi, Vietnam. ${ }^{3}$ Institute of Atomic and Molecular Sciences, Academia Sinica, Taipei 10617, Taiwan, ROC. ${ }^{4}$ Leibniz Institute of Plant Genetics and Crop Plant Research, Gatersleben, Germany.
\end{abstract}

\section{Acknowledgements}

We would like to express special thanks to Dr. Phan Trong Hoang from IPK Gatersleben, Germany for providing plasmid pCB301 and monoclonal anti-cmyc antibody. We are also grateful to Dr. Do Thi Thao from IBT, Hanoi, Vietnam for animal experiments. ND (H7:ND) preparation/characterization, and MDP are supported by a research grant (VAST.DLT.03/17-18) from Vietnam Academy of Science and Technology. We would like to thank Prof. Chau-Chung Han and Dr. Pei-Chang Tsai from IAMS for valuable discussion on ND production and TEM experiment, respectively.

\section{Competing interests}

The authors declare that they have no competing interests.

\section{Availability of data and materials}

The datasets used and/or analysed during the current study are available from the corresponding author on reasonable request.

\section{Consent for publication}

Not applicable.

\section{Ethics approval and consent to participate}

All procedures related to animal experiments were carried out in a bioassay laboratory and approved by the local ethics committee for animals of the Institute of biotechnology (IBT), Vietnam Academy of Science and Technology (VAST), 18 Hoang Quoc Viet, Cau Giay, Ha Noi, Vietnam.

\section{Funding}

This research was supported by VAST through Project: VAST02.03/14-15, in Scientific Program: Biotechnology, code: VAST02.

\section{Publisher's Note}

Springer Nature remains neutral with regard to jurisdictional claims in published maps and institutional affiliations.

Received: 10 April 2017 Accepted: 23 September 2017

Published online: 05 October 2017

\section{References}

1. Chen HW, Huang CY, Lin SY, Fang ZS, Hsu CH, Lin JC, Chen YI, Yao BY, Hu CM. Synthetic virus-like particles prepared via protein corona formation enable effective vaccination in an avian model of coronavirus infection. Biomaterials. 2016;106:111-8.

2. Chen WH, Lee SC, Sabu S, Fang HC, Chung SC, Han CC, Chang HC. Solidphase extraction and elution on diamond (SPEED): a fast and general platform for proteome analysis with mass spectrometry. Anal Chem. 2006:78:4228-34

3. Du L, Zhao G, Sun S, Zhang X, Zhou X, Guo Y, Li Y, Zhou Y, Jiang S. A critical HA1 neutralizing domain of H5N1 influenza in an optimal conformation induces strong cross-protection. PLoS ONE. 2013;8:e53568.

4. Gahrtz M, Conrad U. Immunomodulation of plant function by in vitro selected single-chain Fv intrabodies. Methods Mol Biol. 2009;483:289-312.

5. Han T, Sui J, Bennett A, Liddington R, Donis R, Zhu Q, Marasco W. Fine epitope mapping of monoclonal antibodies against hemagglutinin of a highly pathogenic H5N1 influenza virus using yeast surface display. Biochem Biophys Res Commun. 2011;409:253-9.

6. Hanson MC, Crespo MP, Abraham W, Moynihan KD, Szeto GL, Chen SH, Melo MB, Mueller S, Irvine DJ. Nanoparticulate STING agonists are potent lymph node-targeted vaccine adjuvants. J. Clin. Investig. 2015;125:2532-46.
7. Harbury PB, Zhang T, Kim PS, Alber T. A switch between two-, three-, and four-stranded coiled coils in GCN4 leucine zipper mutants. Science. 1993:262:1401-7.

8. Hsiao WW, Hui YY, Tsai PC, Chang HC. Fluorescent nanodiamond: a versatile tool for long-term cell tracking, super-resolution imaging, and nanoscale temperature sensing. Acc Chem Res. 2016;49:400-7.

9. Hu CMJ, Chien CY, Liu MT, Fang ZS, Chang SY, Juang RH, Chang SC, Chen HW. Multi-antigen avian influenza a (H7N9) virus-like particles: particulate characterizations and immunogenicity evaluation in murine and avian models. BMC Biotechnol. 2017;17:2.

10. Kanekiyo M, Wei CJ, Yassine HM, McTamney PM, Boyington JC, Whittle JRR, Rao SS, Kong WP, Wang L, Nabel GJ. Self-assembling influenza nanoparticle vaccines elicit broadly neutralizing H1N1 antibodies. Nature. 2013:499:102-6.

11. Kong XL, Huang LCL, Hsu CM, Chen WH, Han CC, Chang HC. High-affinity capture of proteins by diamond nanoparticles for mass spectrometric analysis. Anal Chem. 2005;77:259-65.

12. Liu YV, Massare MJ, Pearce MB, Sun X, Belser JA, Maines TR, Creager HM, Glenn GM, Pushko P, Smith GE, Tumpey TM. Recombinant virus-like particles elicit protective immunity against avian influenza A (H7N9) virus infection in ferrets. Vaccine. 2015;33:2152-8.

13. Ma W, Brenner D, Wang Z, Dauber B, Ehrhardt C, Högner K, Herold S, Ludwig S, WolffT, Yu K, Richt JA, Planz O, Pleschka S. The NS-segment of an H5N1 highly pathogenic avian influenza virus (HPAIV) is sufficient to alter replication efficiency, cell tropism and host range of an H7N1 HPAIV. J Virol. 2010;84:2122-33.

14. Mochalin VN, Shenderova O, Ho D, Gogotsi Y. The properties and applications of nanodiamonds. Nat Nanotechnol. 2011;7:11-23.

15. Narayan R. Diamond-based materials for biomedical applications. 1st ed. Illinois: Woodhead, Print Book \& E-Book; 2013. ISBN 9780857093400, 9780857093516

16. Noad R, Roy P. Virus-like particles as immunogens. Trends Microbiol. 2003:11:438-44.

17. Pham MD, Yu SSF, Han CC, Chan SI. Improved mass spectrometric analysis of membrane proteins based on rapid and versatile sample preparation on nanodiamond particles. Anal Chem. 2013;85:6748-55.

18. Pham MD, Wen TC, Li HC, Hsieh PH, Chen YR, Chang HC, Han CC. Streamlined membrane proteome preparation for shotgun proteomics analysis with triton X-100 cloud point extraction and nanodiamond solid phase extraction. Materials. 2016:9:385.

19. Phan HT, Hause B, Hause G, Arcalis E, Stoger E, Maresch D, Altmann F, Joensuu J, Conrad U. Influence of elastin-like polypeptide and hydrophobin on recombinant hemagglutinin accumulations in transgenic tobacco plants. PLoS ONE. 2014:9:e99347.

20. Phan HT, Pohl J, Floss DM, Rabenstein F, Veits J, Le BT, Chu HH, Hause G, Mettenleiter T, Conrad U. ELPylated hemagglutinins produced in tobacco plants induce potentially neutralizing antibodies against $\mathrm{H} 5 \mathrm{~N} 1$ viruses in mice. Plant Biotechnol J. 2013;11:582-93.

21. Pillet $S$, Racine T, Nfon C, Di Lenardo TZ, Babiuk S, Ward BJ, Kobinger GP, Landry N. Plant-derived H7 VLP vaccine elicits protective immune response against $\mathrm{H} 7 \mathrm{~N} 9$ influenza virus in mice and ferrets. Vaccine. 2015;33:6282-9.

22. Pulendran B, Ahmed R. Immunological mechanisms of vaccination. Nat Immunol. 2011;12:509-17.

23. Pushko P, Pujanauski LM, Sun X, Pearce $M$, Hidajat $R$, Kort $T$, Schwartzman LM, Tretyakova I, Chunqing L, Taubenberger JK, Tumpey TM. Recombinant $\mathrm{H} 7$ hemagglutinin forms subviral particles that protect mice and ferrets from challenge with H7N9 influenza virus. Vaccine. 2015;33:4975-82.

24. Sahdev P, Ochyl $L$, Moon JJ. Biomaterials for nanoparticle vaccine delivery systems. Pharm Res. 2014;31:2563-82.

25. Schirmbeck R, Melber K, Reimann J. Hepatitis B virus small surface antigen particles are processed in a novel endosomal pathway for major histocompatibility complex class I-restricted epitope presentation. Eur J Immunol. 1995;25:1063-70.

26. Singh M, Chakrapani A, O'Hagan D. Nanoparticles and microparticles as vaccine-delivery systems. Expert Rev Vaccines. 2007;6:797-808.

27. Wei CJ, Xu L, Kong WP, Shi W, Canis K, Stevens J, Yang ZY, Dell A, Haslam SM, Wilson IA, Nabel GJ. Comparative efficacy of neutralizing antibodies elicited by recombinant hemagglutinin proteins from avian $\mathrm{H} 5 \mathrm{~N} 1$ influenza virus. J Virol. 2008;82:6200-8. 
28. Weldon WC, Wang BZ, Martin MP, Koutsonanos DG, Skountzou I. Enhanced immunogenicity of stabilized trimeric soluble influenza hemagglutinin. PLOS ONE. 2010;5:e12466.

29. World Health Organization. Human infections with avian influenza A (H7N9) virus. http://www.who.int/influenza/human_animal interface/ influenza_h7n9/Risk_Assessment/en/. Accessed 10 Feb 2017.

30. World Organization for Animal Health (OIE). Highly pathogenic avian influenza, in manual of diagnostic tests and vaccines for terrestrial animals (mammals, birds, and bees). Paris: World Organization for Animal Health (OIE); 2004. p. 259-69.

31. Xiang SD, Scholzen A, Minigo G, David C, Apostolopoulos V. Pathogen recognition and development of particulate vaccines: does size matter? Methods. 2006;40:1-9.

32. Zhao L, Seth A, Wibowo N, Zhao CX, Mitter N. Nanoparticle vaccines. Vaccine. 2014;32:327-37.

\section{Submit your next manuscript to BioMed Central and we will help you at every step:}

- We accept pre-submission inquiries

- Our selector tool helps you to find the most relevant journal

- We provide round the clock customer support

- Convenient online submission

- Thorough peer review

- Inclusion in PubMed and all major indexing services

- Maximum visibility for your research

Submit your manuscript at www.biomedcentral com/submit 